\title{
Nanocomposite Polymers with "Slimy" Surfaces that Refresh Following Abrasion
}

\author{
Wenshou Wang ${ }^{1}$, Ronald A. Siegel ${ }^{1,2, *}$, Chun Wang ${ }^{1, *}$ \\ ${ }^{1}$ Department of Biomedical Engineering, ${ }^{2}$ Department of Pharmaceutics, University of \\ Minnesota, Minneapolis, MN, USA \\ *Corresponding authors: siege017@umn.edu,wangx504@umn.edu
}

\section{SUPPORTING INFORMATION}

4 pages, 3 figures 

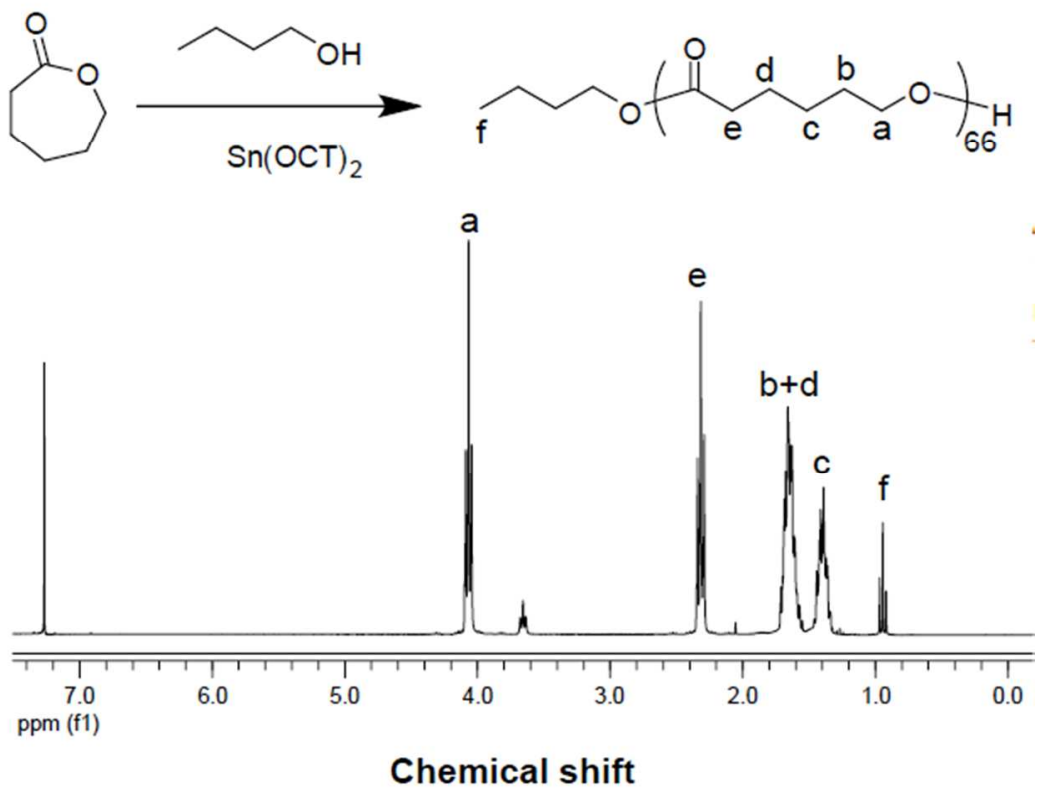

Figure S1. Ring-opening polymerization to prepare short-chain semitelechilic PCL with one hydroxyl end group (PCL-OH) and ${ }^{1} \mathrm{H}$ NMR spectrum of the product in $\mathrm{CDCl}_{3}$. The average molecular weight of the PCL was calculated as $M_{\mathrm{n}}=\left(3 I_{\mathrm{a}} / 2 I_{\mathrm{f}}\right) \times 114+74$, where $I_{\mathrm{a}}$ and $I_{\mathrm{f}}$ are areas of peak "a" and "f", respectively. The molecular weight of the PCL repeating unit is 114 and that of the initiator is 74 . 


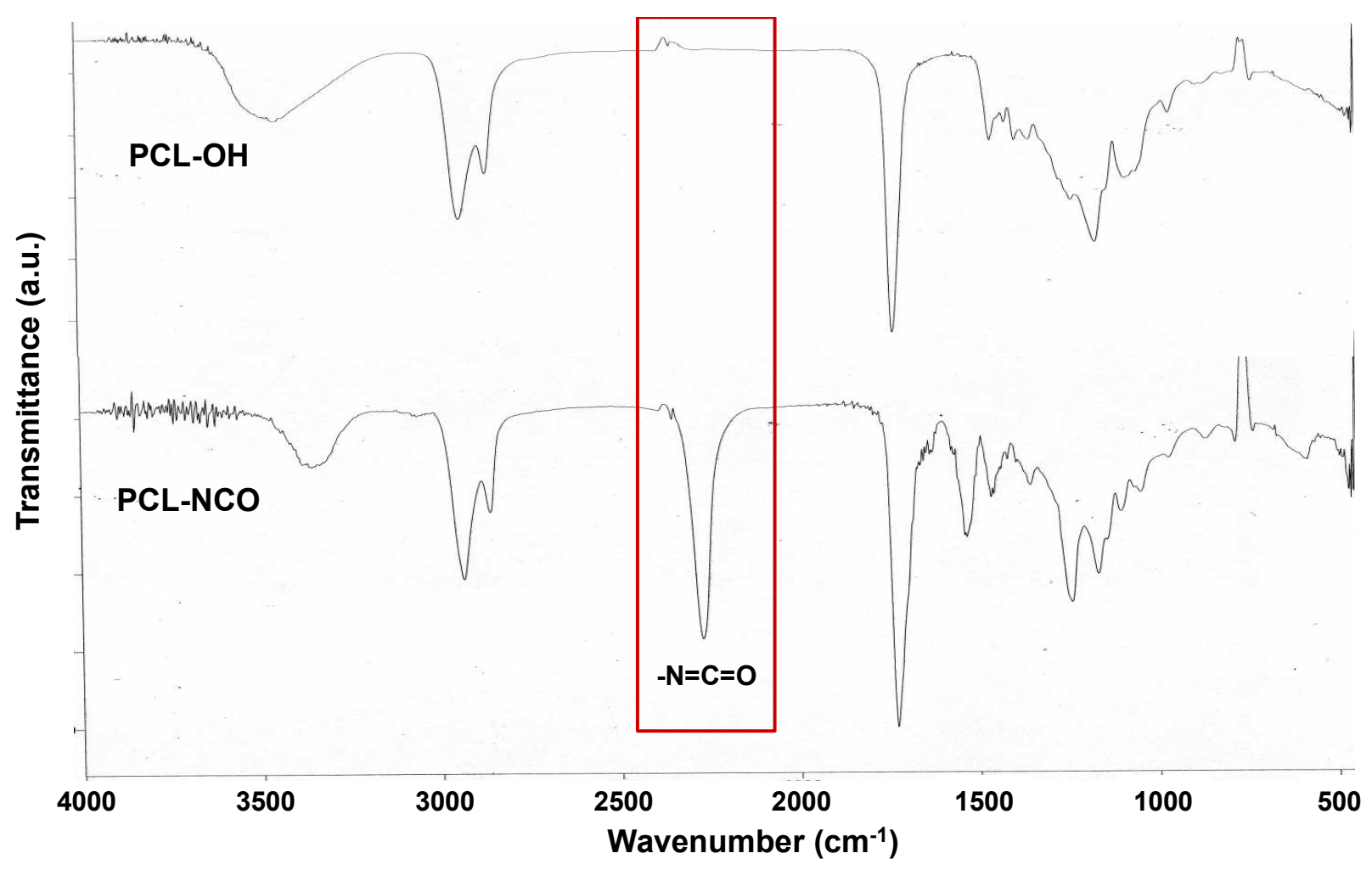

Figure S2. FTIR spectra of PCL-OH and PCL-NCO. The appearance of the characteristic absorption of the $-\mathrm{N}=\mathrm{C}=\mathrm{O}$ at $2270 \mathrm{~cm}^{-1}$ is noted. 

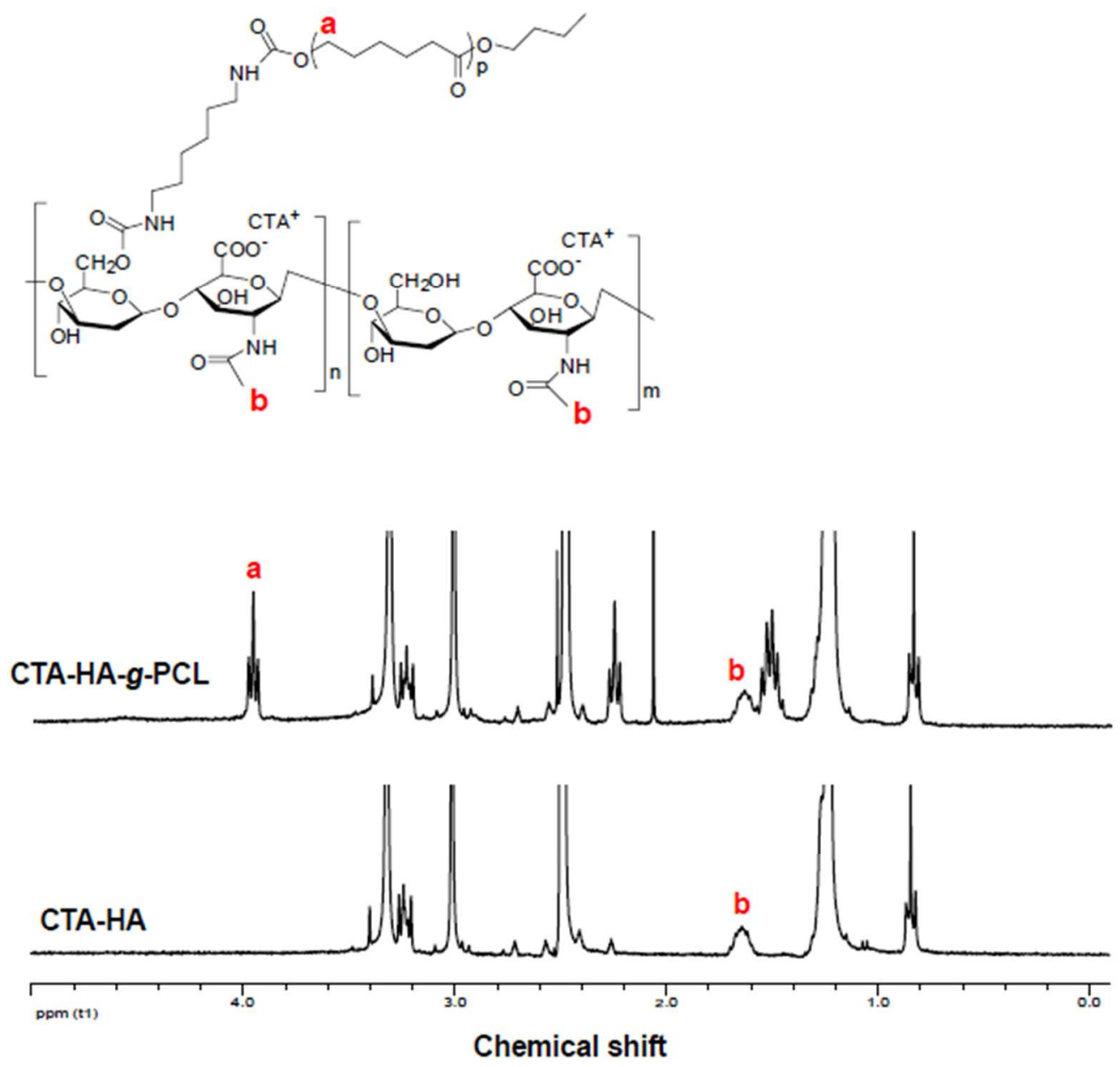

Figure S3. ${ }^{1} \mathrm{H}$ NMR spectra of CTA-HA-g-PCL and CTA-HA in DMSO- $\mathrm{d}_{6}$. The degree of grafting was defined as $n /(m+n)$, where $m$ and $n$ are the numbers of HA disacharride units without or with PCL chains attached, respectively. It was calculated as $3 I_{\mathrm{a}} /\left(2 I_{\mathrm{b}} \times 66\right)$ in percentage, where $I_{\mathrm{a}}$ and $I_{\mathrm{b}}$ are the areas of peak "a" and "b", respectively. 